\title{
In Situ Study of Thermal Stability of Copper Oxide Nanowires at Anaerobic Environment
}

\author{
Lihui Zhang, ${ }^{1}$ Qiong Feng, ${ }^{2}$ Anmin Nie,, Jiabin Liu, ${ }^{1,3}$ Hongtao Wang, ${ }^{2}$ and Youtong Fang1 \\ ${ }^{1}$ College of Electrical Engineering, Zhejiang University, Hangzhou 310027, China \\ ${ }^{2}$ Institute of Applied Mechanics, Zhejiang University, Hangzhou 310027, China \\ ${ }^{3}$ Department of Materials Science and Engineering, Zhejiang University, Hangzhou 310027, China
}

Correspondence should be addressed to Jiabin Liu; liujiabin@zju.edu.cn and Hongtao Wang; htw@zju.edu.cn

Received 27 May 2014; Accepted 24 June 2014; Published 24 July 2014

Academic Editor: Vladimir Sivakov

Copyright (C) 2014 Lihui Zhang et al. This is an open access article distributed under the Creative Commons Attribution License, which permits unrestricted use, distribution, and reproduction in any medium, provided the original work is properly cited.

Many metal oxides with promising electrochemical properties were developed recently. Before those metal oxides realize the use as an anode in lithium ion batteries, their thermal stability at anaerobic environment inside batteries should be clearly understood for safety. In this study, copper oxide nanowires were investigated as an example. Several kinds of in situ experiment methods including in situ optical microscopy, in situ Raman spectrum, and in situ transmission electron microscopy were adopted to fully investigate their thermal stability at anaerobic environment. Copper oxide nanowires begin to transform as copper(I) oxide at about $250^{\circ} \mathrm{C}$ and finish at about $400^{\circ} \mathrm{C}$. The phase transformation proceeds with a homogeneous nucleation.

\section{Introduction}

Energy issues become more and more important today than those at any time in the past. Lithium ion batteries (LIBs), as one of the most promising technologies, have obtained high attentions in both industry and science societies. Important advances have been made for further improving the battery properties recently, such as the developments of $\mathrm{Li}-\mathrm{O}_{2}$ and Li-S batteries, Na-ion batteries, and double-walled silicon nanotube batteries [1-6].

The anode material is one of the most important components in LIBs. Graphite was the first commercialized anode material due to its good cycle performance. However, relatively low theoretical capacity $(\sim 372 \mathrm{mAh} / \mathrm{g})$ of graphite stimulated the study of other high energy density anode materials [7]. A number of anode materials, such as aluminum $[8,9]$, tin $[10,11]$, germanium $[12,13]$, and silicon $[14,15]$ were developed over the past few years $[6,7,16-20]$.

Metal oxides, expected to be important anode materials in the future, have high theoretical capacity. $\mathrm{SnO}_{2}, \mathrm{Co}_{3} \mathrm{O}_{4}$, $\mathrm{RuO}_{2}$, and $\mathrm{TiO}_{2}$ anodes [18, 21-26] have several advantages compared to others. The research team headed by Huang et al. revealed the charge-discharge lithium mechanism of metal oxide nanowires by in situ lithiation-delithiation in transmission electron microscopy (TEM) [27, 28]. Those researchers have greatly enhanced our understanding of the charge-discharge lithium mechanism of metal oxides and promoted the development of science and technology.

Metal oxides have high thermal stability in the oxygen environment. However whether they have high thermal stability at anaerobic environment in LIBs is still an open question. The accidents of "Boeing $787 \mathrm{~s}$ " overheated batteries and "Sony" notebooks remind us that the thermal problems should never be an afterthought or dealt with lightly. The temperature in the batteries would significantly increase when the batteries are working at high current density. Some local areas may reach a rather high temperature due to the complicated and inhomogeneous microstructure of the anodes. The situation would be more significant for the $\mathrm{Na} / \mathrm{S}$ and $\mathrm{Na} / \mathrm{NiCl}_{2}$ systems operating at higher temperatures $\left(300-350^{\circ} \mathrm{C}\right)[29]$. However, it is nearly a fresh area for the research on thermal stability of metal oxides in such a high temperature anaerobic environment.

Copper oxide nanomaterials have attracted great attentions and have demonstrated significant performances as anode materials [30-32]. It was reported that the capacity of the attenuation was less than $10 \%$ after 70 cycles and the cyclic capacity maintained at $400 \mathrm{mAh} / \mathrm{g}$ when using copper oxide 


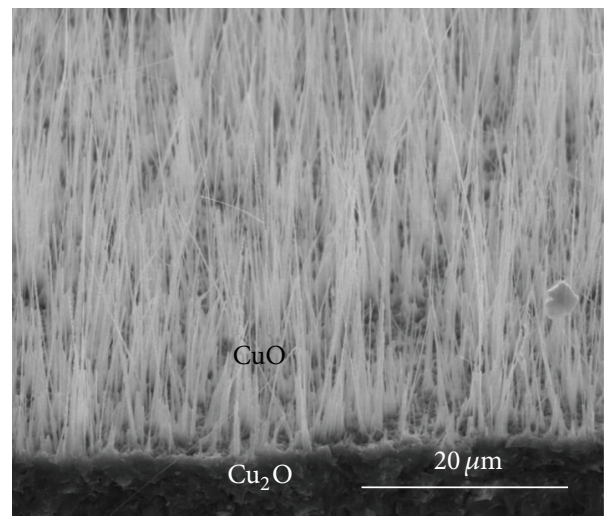

(a)

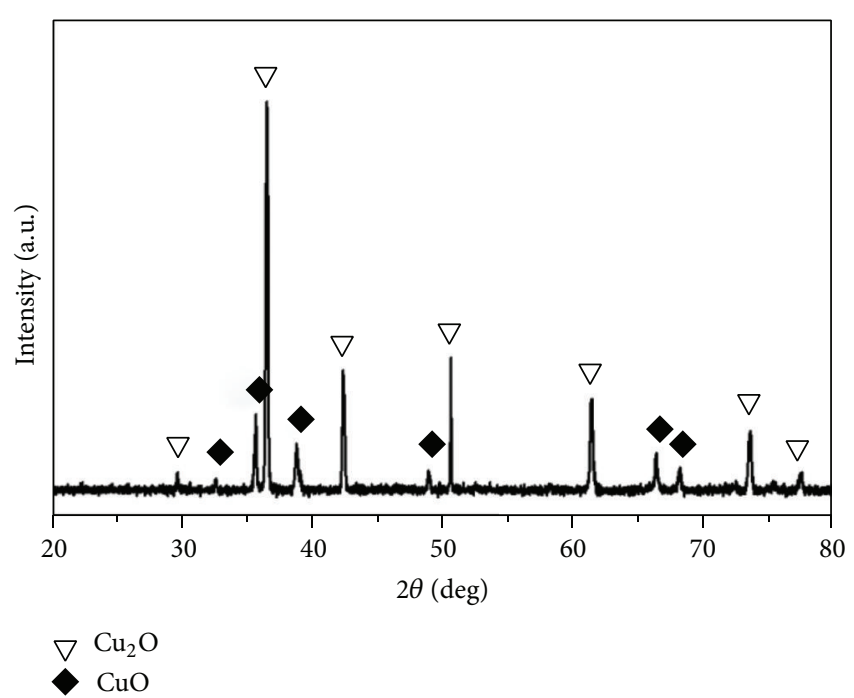

(b)

FIGURE 1: (a) SEM image of $\mathrm{Cu}$ foil oxide layer and (b) XRD pattern of $\mathrm{Cu}$ foil oxide layer.

nanowires as anodes [33]. Further improvement has been obtained that the cyclic capacity of copper oxide film could remain at $608 \mathrm{mAh} / \mathrm{g}$ with a current density of $100 \mathrm{~mA} / \mathrm{g}$ after 275 cycles, which reached $90 \%$ of the theoretical capacity [3437].

In this study, copper oxide nanowires were investigated as an example. Several in situ tests were adopted to explore the thermal stability of copper oxide nanowires at anaerobic environment directly. In situ optical microscopy, in situ Raman, and in situ TEM were carried out to study both the morphology and structure evolutions during in situ heating.

\section{Materials and Methods}

$\mathrm{Cu}$ foils (99.9\% purity, Alfa Aesar Company) with a thickness of $25 \mu \mathrm{m}$ were cleaned in an aqueous $1.0 \mathrm{~mol} / \mathrm{L} \mathrm{HCl}$ solution for $5 \sim 10 \mathrm{~s}$, followed by repeated 2-3 times rinsing with deionized water. $\mathrm{Cu}$ foils were dried under $\mathrm{N}_{2}$ gas flow, then placed in a rapid thermal processing system furnace (JET FIRST-200), and then heated to $500^{\circ} \mathrm{C}$ for $5 \mathrm{~h}$ in air ambient with a heating rate of $40^{\circ} \mathrm{C} / \mathrm{s}$.

The crystal structure of copper oxide was analyzed by $\mathrm{X}$-ray diffraction (XRD, X'Pert $\mathrm{PRO}$ ) with $\mathrm{Cu}-\mathrm{K} \alpha$ radiation from $10^{\circ}$ to $90^{\circ}$. The microstructure of the copper oxides was observed by scanning electron microscope (SEM, Hitachi S3700) and TEM (FEI F30). Some copper oxide nanowires were heated to a maximum temperature of $400^{\circ} \mathrm{C}$ with nitrogen atmosphere protection. The morphology change of the copper oxide nanowires was in situ observed under the optical microscope equipped in the Raman test system and the structure change of the copper oxide nanowires was in situ analyzed by Raman test during heating. The Raman spectra were recorded by using a LabRamHRUV instrument equipped with a $532 \mathrm{~nm}$ laser excitation. The microstructure change of the copper nanowires was in situ investigated in the TEM equipped with an in situ heating holder (Gatan 652).

\section{Results and Discussion}

High-density copper oxide nanowires are obtained when copper foils were oxidized in air ambient at $500^{\circ} \mathrm{C}$ for $5 \mathrm{~h}$ (Figure 1(a)). The average diameter of the nanowires is about $65 \mathrm{~nm}$ and the length of the nanowires is up to $20 \mu \mathrm{m}$. XRD pattern of the sample in Figure 1(a) indicates the coexistence of $\mathrm{CuO}$ phase of monoclinic structure (JCPDS80-1917) and $\mathrm{Cu}_{2} \mathrm{O}$ phase of cubic structure (JCPDS78-2076) in the oxide layer (Figure $1(\mathrm{~b})$ ). The majority phase is the $\mathrm{Cu}_{2} \mathrm{O}$, which is in well accordance with previous studies [38]. Copper is always first oxidized into the $\mathrm{Cu}_{2} \mathrm{O}$ phase and the subsequent formation of $\mathrm{CuO}$ phase would be very slow due to the cover of $\mathrm{Cu}_{2} \mathrm{O}$ layer.

Figure 2(a) shows the TEM image of an individual nanowire with a diameter of about $60 \mathrm{~nm}$. There is an interface obviously in the middle of nanowire which divides the nanowire into two planes along the longitudinal axis. The interface is confirmed to be twin boundary by select area electron diffraction (SAED) pattern analysis as shown in Figure 2(b). The nanowire is confirmed to be $\mathrm{CuO}$ nanowire by measuring the distance and angle of the diffraction spots in the SAED pattern. The SAED pattern corresponds to the two sets of lattice. One set diffraction spot of lattice is observed along the [110] direction while the other is observed along $[1 \overline{1} 0]$. High resolution TEM image clearly shows that the twin boundary is parallel with the (001) plane in Figure 2(c).

The morphology changes of the $\mathrm{CuO}$ nanowire at different temperatures at anaerobic environment were investigated by in situ heating an individual $\mathrm{CuO}$ nanowire with nitrogen atmosphere protection under an optical microscope. $\mathrm{CuO}$ nanowire has no obvious change when temperature is below $250^{\circ} \mathrm{C}$ (Figure $3(\mathrm{a})$ ). When heating temperature reaches $300^{\circ} \mathrm{C}$, some changes occur as pointed by the arrow in Figure 3(b). More changes appear as the temperature increases to $350^{\circ} \mathrm{C}$ (Figure 3(c)). Almost the entire nanowire 

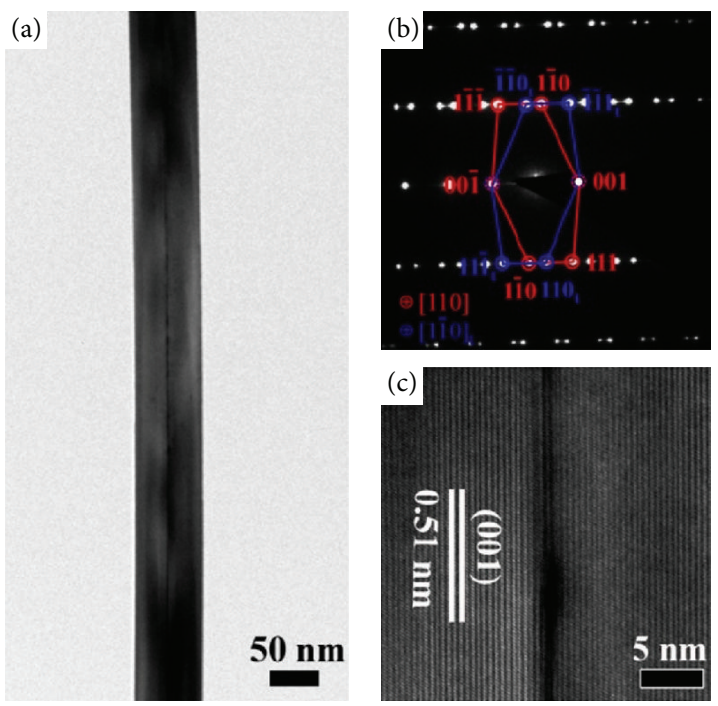

Figure 2: (a) TEM image of an individual $\mathrm{CuO}$ nanowire, (b) SAED pattern of the single nanowire, and (c) corresponding high resolution TEM image.

changes when the temperature increases to $400^{\circ} \mathrm{C}$. The morphology changes of the nanowire indicate that there should be some transformation of the structure of $\mathrm{CuO}$ phase during the in situ heating process with a homogeneous nucleation behavior.

To analyze the structure change of the $\mathrm{CuO}$ nanowire during in situ heating process, in situ Raman test was carried out for the $\mathrm{CuO}$ nanowire heated at the same temperatures with nitrogen atmosphere protection (Figure 4). There are three Raman peaks at $296 \mathrm{~cm}^{-1}, 345 \mathrm{~cm}^{-1}$, and $630 \mathrm{~cm}^{-1}$ for the test nanowire from $25^{\circ} \mathrm{C}$ to $250^{\circ} \mathrm{C}$, which correspond to the $\mathrm{A}_{\mathrm{g}}$, $\mathrm{B}_{1 \mathrm{~g}}$, and $\mathrm{B}_{2 \mathrm{~g}}$ modes [39] of $\mathrm{CuO}$ phase, respectively. When heating temperature reaches $300^{\circ} \mathrm{C}$, two small new Raman peaks emerge at $154 \mathrm{~cm}^{-1}$ and $218 \mathrm{~cm}^{-1}$, which consists with the Raman peaks of $\mathrm{Cu}_{2} \mathrm{O}$ phase [40]. When the temperature continuously increases to $350^{\circ} \mathrm{C}$ and $400^{\circ} \mathrm{C}$, the former three Raman peaks of $\mathrm{CuO}$ phase almost disappear and the two Raman peaks of $\mathrm{Cu}_{2} \mathrm{O}$ phase enhance. Combining the in situ optical observation with Raman test results, it is reasonable to deduce that $\mathrm{CuO}$ phase should be transformed into $\mathrm{Cu}_{2} \mathrm{O}$ with the increase in temperature under nitrogen atmosphere. The phase transformation begins at about $300^{\circ} \mathrm{C}$ and finishes at about $350^{\circ} \mathrm{C}$.

For further study of the thermal stability of $\mathrm{CuO}$ nanowires, in-situ TEM heating experiments of $\mathrm{CuO}$ nanowires were carried out in vacuum of $10^{-6} \mathrm{~Pa}$ with heating holder. TEM images and corresponding SAED patterns of the in situ heated $\mathrm{CuO}$ nanowire are shown in Figure 5. There is no obvious change of morphology or SAED patterns of the $\mathrm{CuO}$ nanowire at temperatures below $200^{\circ} \mathrm{C}$. The $\mathrm{CuO}$ nanowire is coated by a layer of amorphous carbon due to the heating and deposition effect in TEM. As the temperature increases to $250^{\circ} \mathrm{C}$, some changes of $\mathrm{CuO} N W$ from the SAED patterns are noticed as pointed by arrows in Figure 5. At the same time, some slight new diffraction spots form as

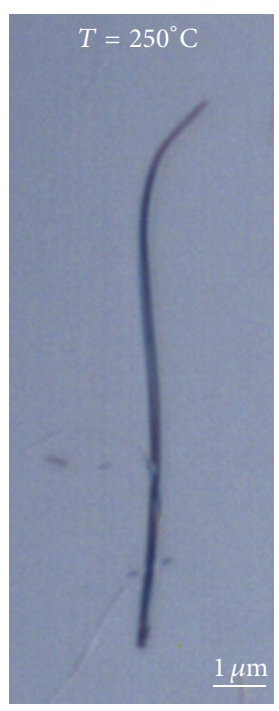

(a)

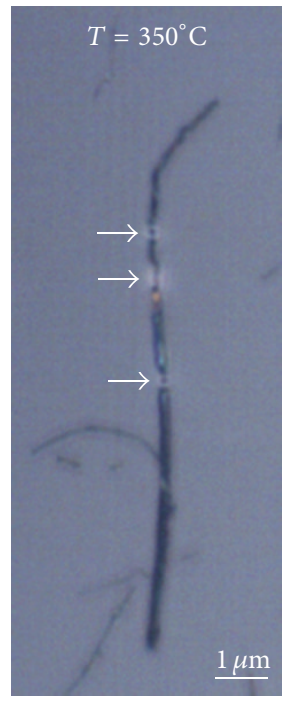

(c)

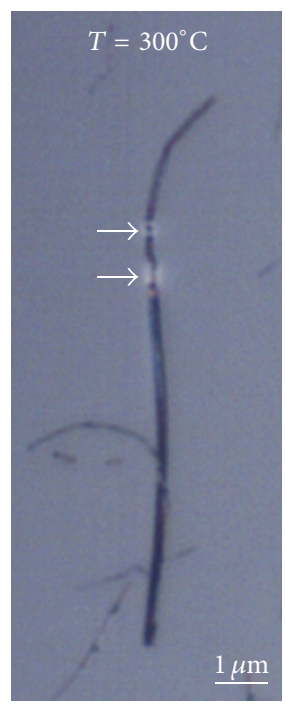

(b)

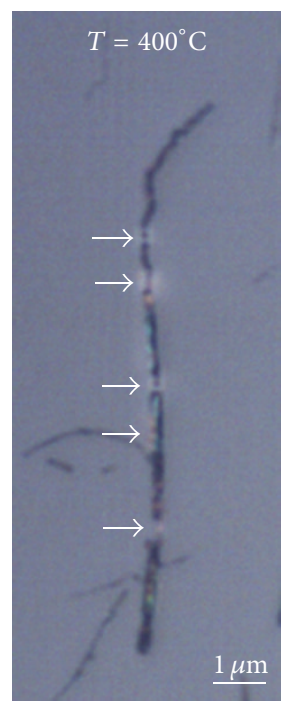

(d)
FIGURE 3: Optical microscopy images of the $\mathrm{CuO}$ nanowire in situ heated at different temperatures with nitrogen atmosphere protection (a) $250^{\circ} \mathrm{C}$, (b) $300^{\circ} \mathrm{C}$, (c) $350^{\circ} \mathrm{C}$, and (d) $400^{\circ} \mathrm{C}$.

indicated by arrows in the SAED patterns. Further increasing the temperature to $300^{\circ} \mathrm{C}$ and $350^{\circ} \mathrm{C}$ results in more obvious changes of the nanowire morphology and more new diffraction spots. When the temperature reaches $400^{\circ} \mathrm{C}$, the original [110] $\mathrm{CuO}$ diffraction spots nearly disappear and the individual $\mathrm{CuO}$ nanowire is transformed into plenty of $\mathrm{Cu}_{2} \mathrm{O}$ nanograins with a homogeneous nucleation mode. The new generated diffraction spots are well consistent with the SAED pattern of $\mathrm{Cu}_{2} \mathrm{O}$ along the [1111] zone axis. The new spots which emerged at $250^{\circ} \mathrm{C}, 300^{\circ} \mathrm{C}$, and $350^{\circ} \mathrm{C}$ are determined to belong to the SAED patterns of $[\overline{1} 11]_{\mathrm{Cu}_{2} \mathrm{O}}$ by carefully analyzing and comparing the SAED patterns in Figure 5. The in situ TEM results agree well with the results of in situ optical microscope observation and in situ Raman test. The start phase transformation temperature detected in in situ TEM is 


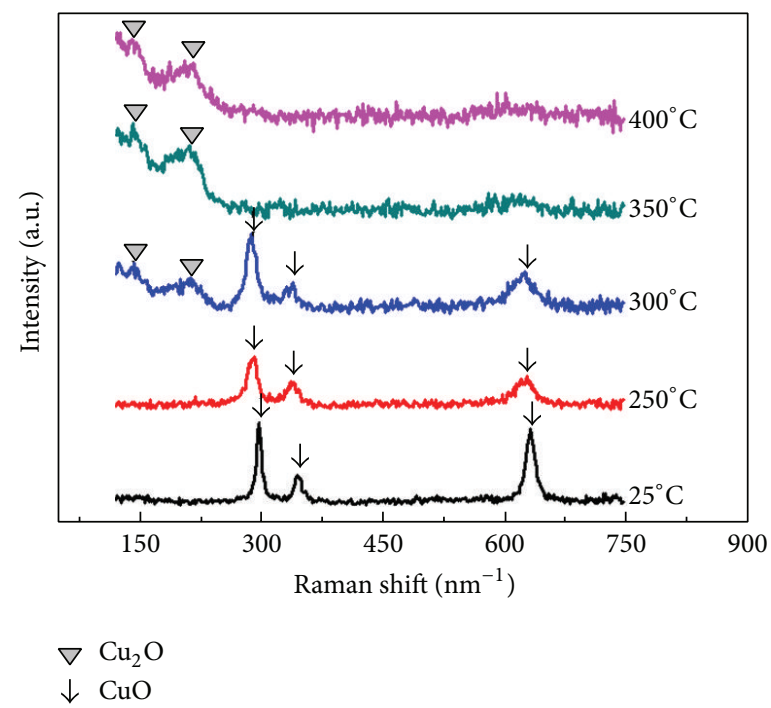

FIgURE 4: In situ Raman spectra of the $\mathrm{CuO}$ nanowire heated at different temperatures with nitrogen atmosphere protection.

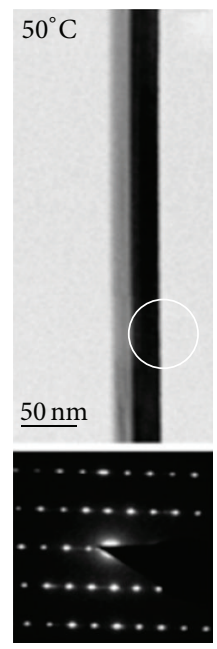

$\mathrm{CuO}$

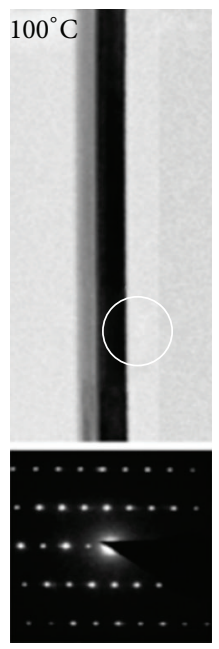

$\mathrm{CuO}$
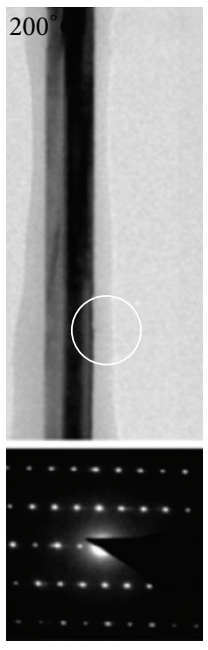

$\mathrm{CuO}$

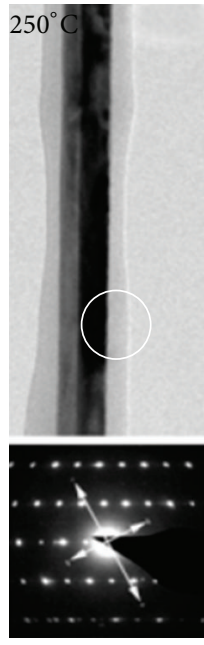

$\mathrm{CuO}$

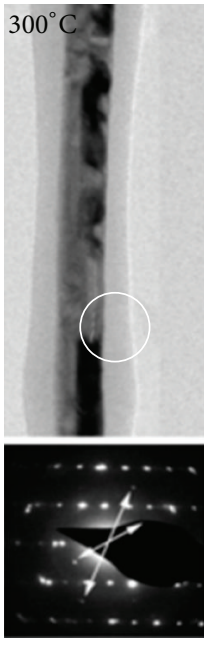

$\mathrm{CuO}$
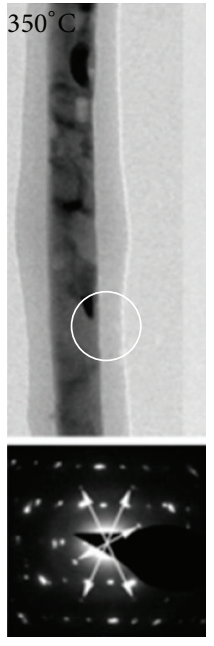

$\mathrm{CuO}$

$\mathrm{Cu}_{2} \mathrm{O}$

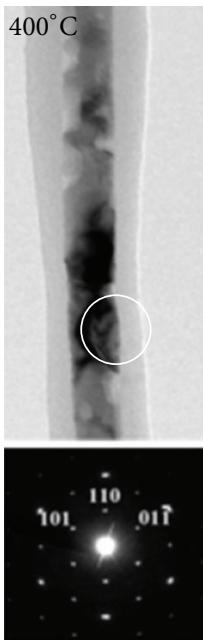

$\mathrm{Cu}_{2} \mathrm{O}$

FIGURE 5: TEM images and SAED patterns corresponding to the white circle of an individual CuO nanowire in situ heated to different temperatures.

about $250^{\circ} \mathrm{C}$ while the temperature is about $300^{\circ} \mathrm{C}$ detected by in situ optical microscope and in situ Raman spectrum. The minor deviation of the start temperature should be attributed to the high resolution of the TEM technology. The above results are consistent well with the phase diagram determining the boundaries of temperature and oxygen pressure for maintaining the stability of $\mathrm{Cu}, \mathrm{Cu}_{2} \mathrm{O}$, and $\mathrm{CuO}$ by Rakhshani [41]. It was believed that the $\mathrm{CuO}$ phase could be stabilized until $300^{\circ} \mathrm{C}$ at a very low oxygen pressure. In this study the phase transformation of $\mathrm{CuO}$ to $\mathrm{Cu}_{2} \mathrm{O}$ begins at $250^{\circ} \mathrm{C}$. The reason may be due to the nanoscale effect, which commonly decreases the melting temperature and phase transformation temperature as frequently reported in other nanomaterials [42-46]. Considering that the electrical resistivity of $\mathrm{Cu}_{2} \mathrm{O}$ is three orders higher than that of $\mathrm{CuO}$ [41], the intrinsic resistivity of the LIBs would be greatly enhanced once some of $\mathrm{CuO}$ phase transformed into $\mathrm{Cu}_{2} \mathrm{O}$ phase when the $\mathrm{CuO}$ is used as cathode. As a result, overheating or even explosion may be triggered when such LIBs are charged.

\section{Conclusions}

In this study, copper oxide nanowires were grown by a simple thermal oxide method. The average diameter of nanowires is $65 \mathrm{~nm}$ and the length is up to $20 \mu \mathrm{m}$. In situ Raman and optical microscope tests reveal that copper oxide nanowires gradually change into copper(I) oxide particles during in situ heating at anaerobic environment. In situ TEM test 
further confirms that copper oxide begins to transform into copper(I) oxide at $250^{\circ} \mathrm{C}$ and nearly finish at $400^{\circ} \mathrm{C}$ with a homogeneous nucleation behavior.

\section{Conflict of Interests}

The authors declare that there is no conflict of interests regarding the publication of this paper.

\section{Acknowledgments}

This work has been supported by the National Science Foundation of China (Grant nos. 11322219, 11002124, 11202183, and 51107119) and the National High Technology Research and Development Program (863) of China (no. 2011AA11A101).

\section{References}

[1] P. G. Bruce, S. A. Freunberger, L. J. Hardwick, and J. Tarascon, "LigO 2 and LigS batteries with high energy storage," Nature Materials, vol. 11, no. 1, pp. 19-29, 2012.

[2] Y. Nomura, I. V. Anoshkin, C. Okuda et al., "Carbon nanotube/nanofibers and graphite hybrids for li-ion battery application," Journal of Nanomaterials, vol. 2014, Article ID 586241, 7 pages, 2014.

[3] J. Tarascon, "Is lithium the new gold?" Nature Chemistry, vol. 2, no. 6, p. 510, 2010.

[4] B. L. Ellis, W. R. M. Makahnouk, Y. Makimura, K. Toghill, and L. F. Nazar, "A multifunctional 3.5 V iron-based phosphate cathode for rechargeable batteries," Nature Materials, vol. 6, no. 10, pp. 749-753, 2007.

[5] J. Christensen, P. Albertus, R. S. Sanchez-Carrera et al., "A critical review of Li/air batteries," Journal of the Electrochemical Society, vol. 159, no. 2, pp. R1-R30, 2012.

[6] H. Wu, G. Chan, J. W. Choi et al., "Stable cycling of double-walled silicon nanotube battery anodes through solidelectrolyte interphase control," Nature Nanotechnology, vol. 7, no. 5, pp. 310-315, 2012.

[7] Y. Liu, N. S. Hudak, D. L. Huber, S. J. Limmer, J. P. Sullivan, and J. Y. Huang, "In situ transmission electron microscopy observation of pulverization of aluminum nanowires and evolution of the thin surface $\mathrm{Al}_{2} \mathrm{O}_{3}$ layers during lithiation-delithiation cycles," Nano Letters, vol. 11, no. 10, pp. 4188-4194, 2011.

[8] X. Lei, C. Wang, Z. H. Yi, Y. G. Liang, and J. T. Sun, "Effects of particle size on the electrochemical properties of aluminum powders as anode materials for lithium ion batteries," Journal of Alloys and Compounds, vol. 429, no. 1-2, pp. 311-315, 2007.

[9] Y. Hamon, T. Brousse, F. Jousse, P. Topart, P. Buvat, and D. M. Schleich, "Aluminum negative electrode in lithium ion batteries," Journal of Power Sources, vol. 97-98, pp. 185-187, 2001.

[10] D. Deng, M. G. Kim, J. Y. Lee, and J. Cho, "Green energy storage materials: Nanostructured $\mathrm{TiO}_{2}$ and Sn-based anodes for lithium-ion batteries," Energy and Environmental Science, vol. 2, no. 8, pp. 818-837, 2009.

[11] S.-C. Chao, Y.-C. Yen, Y.-F. Song, Y.-M. Chen, H.-C. Wu, and N.-L. Wu, "A study on the interior microstructures of working Sn particle electrode of Li-ion batteries by in situ X-ray transmission microscopy," Electrochemistry Communications, vol. 12, no. 2, pp. 234-237, 2010.
[12] L. Baggetto and P. H. L. Notten, "Lithium-ion (De)insertion reaction of germanium thin-film electrodes: an electrochemical and in situ XRD study," Journal of the Electrochemical Society, vol. 156, no. 3, pp. A169-A175, 2009.

[13] L. Baggetto, J. K. Keum, J. F. Browning, and G. M. Veith, "Germanium as negative electrode material for sodium-ion batteries," Electrochemistry Communications, vol. 34, pp. 41-44, 2013.

[14] H. Yu, W. W. Zhang, S. Y. Lei, L. B. Lu, C. Sun, and Q. A. Huang, "Study on vibration behavior of doubly clamped silicon nanowires by molecular dynamics," Journal of Nanomaterials, vol. 2012, Article ID 342329, 5 pages, 2012.

[15] J. R. Szczech and S. Jin, "Nanostructured silicon for high capacity lithium battery anodes," Energy and Environmental Science, vol. 4, no. 1, pp. 56-72, 2011.

[16] X. H. Liu, L. Q. Zhang, L. Zhong et al., "Ultrafast electrochemical lithiation of individual Si nanowire anodes," Nano Letters, vol. 11, no. 6, pp. 2251-2258, 2011.

[17] Z. Wang, G. Xie, and L. Gao, "Electrochemical characterization of $\mathrm{Li}_{4} \mathrm{Ti}_{5} \mathrm{O}_{12} / \mathrm{C}$ anode material prepared by starch-sol-assisted rheological phase method for Li-ion battery," Journal of Nanomaterials, vol. 2012, Article ID 876197, 7 pages, 2012.

[18] P. Balaya, H. Li, L. Kienle, and J. Maier, "Fully reversible homogeneous and heterogeneous $\mathrm{Li}$ storage in $\mathrm{RuO}_{2}$ with high capacity," Advanced Functional Materials, vol. 13, no. 8, pp. 621625, 2003.

[19] P. Poizot, S. Laruelle, S. Grugeon, L. Dupont, and J.-M. Tarascon, "Nano-sized transition-metal oxides as negative-electrode materials for lithium-ion batteries," Nature, vol. 407, no. 6803, pp. 496-499, 2000.

[20] C. K. Chan, H. L. Peng, G. Liu et al., "High-performance lithium battery anodes using silicon nanowires," Nature Nanotechnology, vol. 3, no. 1, pp. 31-35, 2008.

[21] Y. Jiang, Y. Sheng, X. Lan et al., "Mechanism and growth of flexible $\mathrm{ZnO}$ nanostructure arrays in a facile controlled way," Journal of Nanomaterials, vol. 2011, Article ID 473629, 12 pages, 2011.

[22] M. Park, G. Wang, Y. Kang, D. Wexler, S. Dou, and H. Liu, "Preparation and electrochemical properties of $\mathrm{SnO}_{2}$ nanowires for application in lithium-ion batteries," Angewandte Chemie, vol. 46, no. 5, pp. 750-753, 2007.

[23] D. Wei, Y. Shen, M. Li et al., "Synthesis and characterization of single-crystalline $\mathrm{SnO}_{2}$ nanowires," Journal of Nanomaterials, vol. 2013, Article ID 761498, 6 pages, 2013.

[24] K. M. Shaju, F. Jiao, A. Débart, and P. G. Bruce, "Mesoporous and nanowire $\mathrm{Co}_{3} \mathrm{O}_{4}$ as negative electrodes for rechargeable lithium batteries," Physical Chemistry Chemical Physics, vol. 9, no. 15, pp. 1837-1842, 2007.

[25] G. Armstrong, A. R. Armstrong, P. G. Bruce, P. Reale, and B. Scrosati, " $\mathrm{TiO}_{2}(\mathrm{~B})$ nanowires as an improved anode material for lithium-ion batteries containing $\mathrm{LiFePO}_{4}$ or $\mathrm{LiNi}_{0.5} \mathrm{Mn}_{1.5 \mathrm{O} 4}$ cathodes and a polymer electrolyte," Advanced Materials, vol. 18, no. 19, pp. 2597-2600, 2006.

[26] A. M. Nie, J. B. Liu, Q. Q. Li et al., "Epitaxial $\mathrm{TiO}_{2} / \mathrm{SnO}_{2}$ coreshell heterostructure by atomic layer deposition," Journal of Materials Chemistry, vol. 22, no. 21, pp. 10665-10671, 2012.

[27] J. Y. Huang, L. Zhong, C. M. Wang et al., "In situ observation of the electrochemical lithiation of a single $\mathrm{SnO}_{2}$ nanowire electrode," Science, vol. 330, no. 6010, pp. 1515-1520, 2010.

[28] J. W. Wang, X. H. Liu, S. X. Mao, and J. Y. Huang, "Microstructural evolution of tin nanoparticles during in situ sodium 
insertion and extraction," Nano Letters, vol. 12, no. 11, pp. 58975902, 2012.

[29] M. D. Slater, D. Kim, E. Lee, and C. S. Johnson, "Sodium-ion batteries," Advanced Functional Materials, vol. 23, no. 8, pp. 947958, 2013.

[30] X. Guan, L. Li, G. Li, Z. Fu, J. Zheng, and T. Yan, "Hierarchical $\mathrm{CuO}$ hollow microspheres: Controlled synthesis for enhanced lithium storage performance," Journal of Alloys and Compounds, vol. 509, no. 7, pp. 3367-3374, 2011.

[31] S. M. Abbas, S. T. Hussain, S. Ali et al., "One-pot synthesis of a composite of monodispersed $\mathrm{CuO}$ nanospheres on carbon nanotubes as anode material for lithium-ion batteries," Journal of Alloys and Compounds, vol. 574, pp. 221-226, 2013.

[32] S. K. Baek, K. R. Lee, and H. K. Cho, "Oxide p-n heterojunction of $\mathrm{Cu}_{2} \mathrm{O} / \mathrm{ZnO}$ nanowires and their photovoltaic performance," Journal of Nanomaterials, vol. 2013, Article ID 421371, 7 pages, 2013.

[33] S. Grugeon, S. Laruelle, R. Herrera-Urbina, L. Dupont, P. Poizot, and J. M. Tarascon, "Particle size effects on the electrochemical performance of copper oxides toward lithium," Journal of the Electrochemical Society, vol. 148, no. 4, pp. A285-A292, 2001.

[34] D. W. Zhang, C. H. Chen, J. Zhang, and F. Ren, "Novel electrochemical milling method to fabricate copper nanoparticles and nanofibers," Chemistry of Materials, vol. 17, no. 21, pp. 5242$5245,2005$.

[35] F. Ke, L. Huang, G. Wei et al., "One-step fabrication of $\mathrm{CuO}$ nanoribbons array electrode and its excellent lithium storage performance," Electrochimica Acta, vol. 54, no. 24, pp. 5825$5829,2009$.

[36] Y. Lee, I. Leu, C. Liao et al., "Fabrication and characterization of $\mathrm{Cu}_{2} \mathrm{O}$ nanorod arrays and their electrochemical performance in Li-ion batteries," Electrochemical and Solid-State Letters, vol. 9, no. 4, pp. A207-A210, 2006.

[37] J. C. Park, J. Kim, H. Kwon, and H. Song, "Gram-scale synthesis of $\mathrm{Cu}_{2} \mathrm{O}$ nanocubes and subsequent oxidation to $\mathrm{CuO}$ hollow nanostructures for Lithium-ion battery anode materials," Advanced Materials, vol. 21, no. 7, pp. 803-807, 2009.

[38] M. Farbod, N. M. Ghaffari, and I. Kazeminezhad, "Effect of growth parameters on photocatalytic properties of $\mathrm{CuO}$ nanowires fabricated by direct oxidation," Materials Letters, vol. 81, pp. 258-260, 2012.

[39] J. F. Xu, W. Ji, Z. X. Shen et al., "Raman spectra of $\mathrm{CuO}$ nanocrystals," Journal of Raman Spectroscopy, vol. 30, no. 5, pp. 413415, 1999.

[40] P. F. Williams and S. P. S. Porto, "Symmetry-forbidden resonant Raman scattering in $\mathrm{Cu}_{2} \mathrm{O}$," Physical Review B, vol. 8, no. 4, pp. 1782-1785, 1973.

[41] A. E. Rakhshani, "Preparation, characteristics and photovoltaic properties of cuprous oxide-a review," Solid State Electronics, vol. 29, no. 1, pp. 7-17, 1986.

[42] A. Safaei, "Shape, structural, and energetic effects on the cohesive energy and melting point of nanocrystals," The Journal of Physical Chemistry C, vol. 114, no. 32, pp. 13482-13496, 2010.

[43] A. Safaei, M. Attarian Shandiz, S. Sanjabi, and Z. H. Barber, "Modeling the melting temperature of nanoparticles by an analytical approach," Journal of Physical Chemistry C, vol. 112, no. 1, pp. 99-105, 2008.

[44] Y. Xue, M. Zhao, and W. Lai, "Size-dependent phase transition temperatures of dispersed systems," Physica B Condensed Matter, vol. 408, no. 1, pp. 134-139, 2013.
[45] W. H. Qi and M. P. Wang, "Size and shape dependent melting temperature of metallic nanoparticles," Materials Chemistry and Physics, vol. 88, no. 2-3, pp. 280-284, 2004.

[46] K. K. Nanda, "Size-dependent melting of nanoparticles: hundred years of thermodynamic model," Pramana, vol. 72, no. 4, pp. 617-628, 2009. 

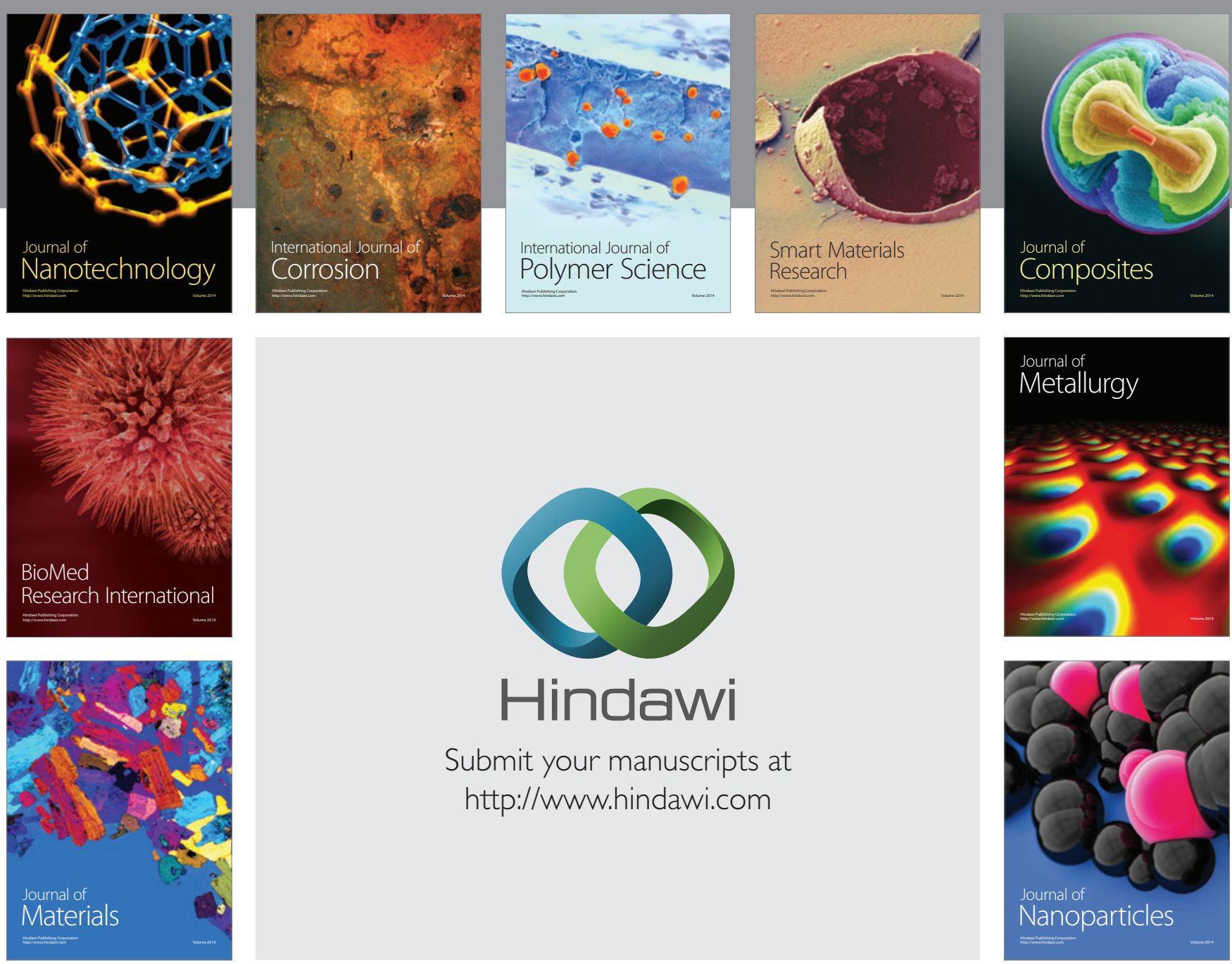

Submit your manuscripts at http://www.hindawi.com
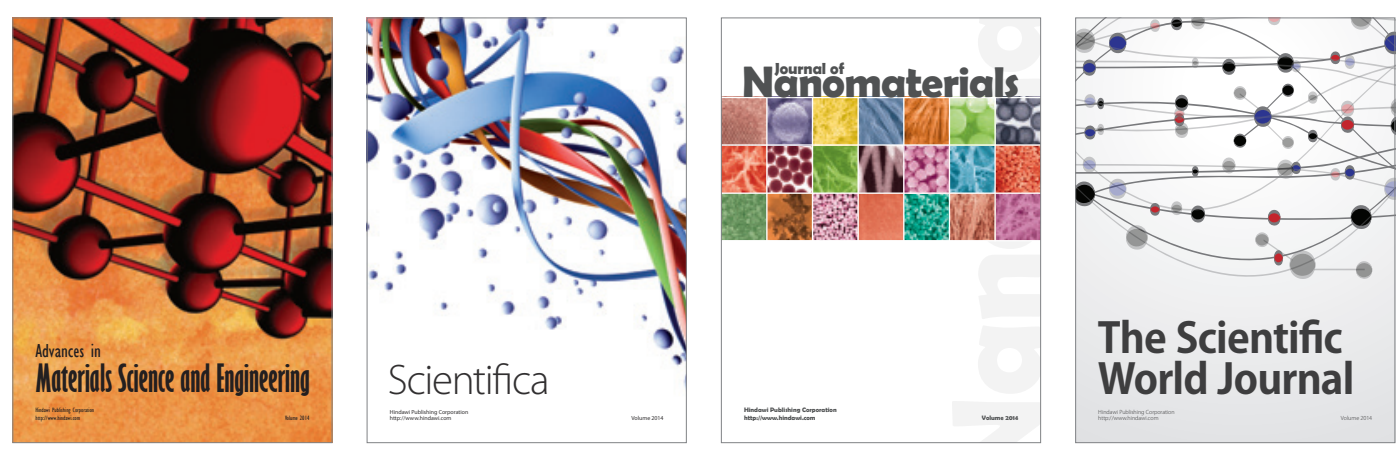

\section{The Scientific World Journal}
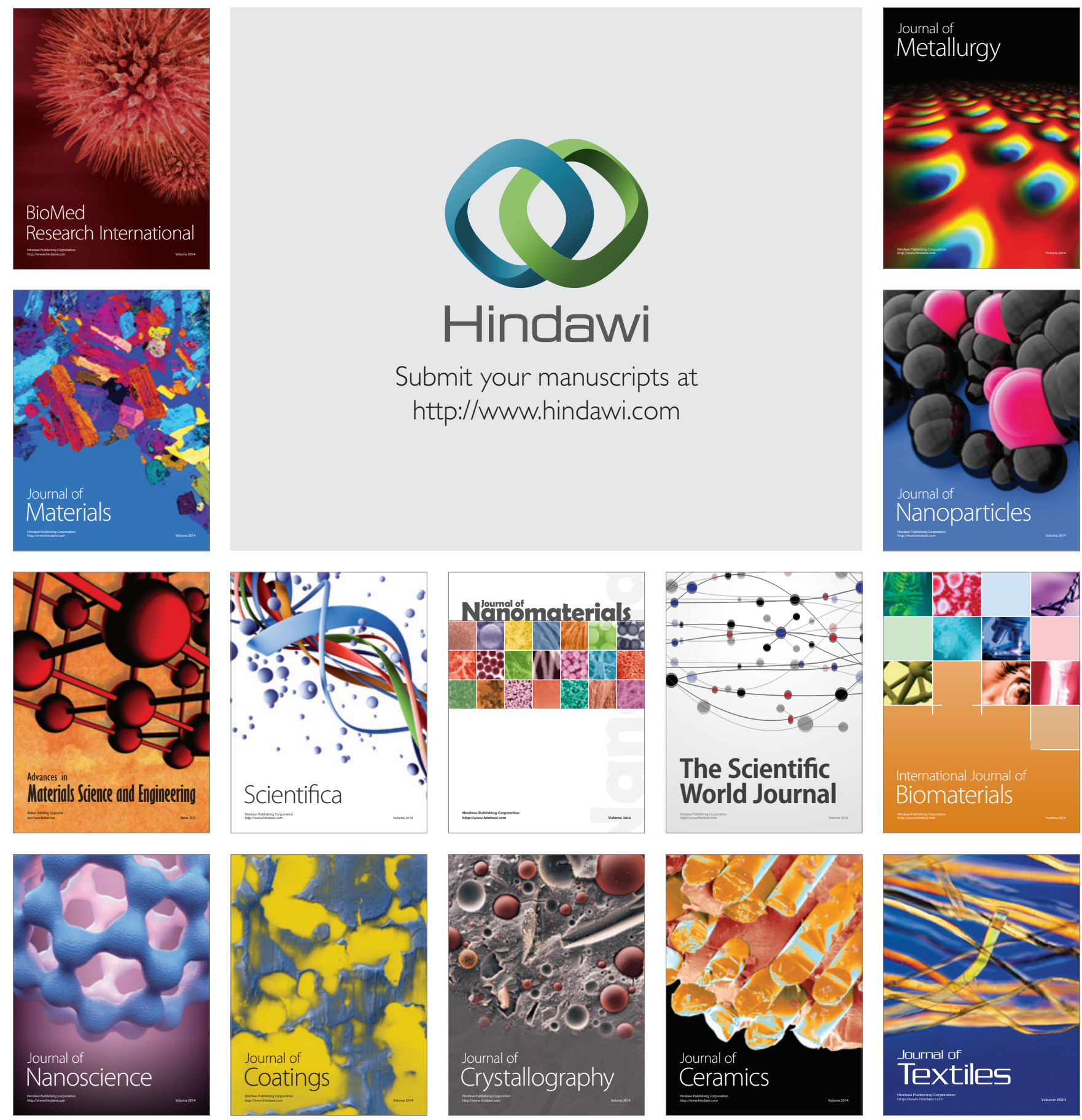